\title{
Herbal medicine used by the community of Koneba district in Afar Regional State, Northeastern Ethiopia
}

\author{
Ali Zeynu' ${ }^{1}$, Tigist Wondimu², Sebsebe Demissew²
}

1. Semera University, Biology Department, Afar, Ethiopia. Email: alizeynu@gmail.com

2. Addis Ababa University, College of Natural and Computational Sciences, Department of Plant Biology and Biodiversity Management; P.O. Box 30251, Addis Ababa, Ethiopia. Email: tigist.wondimu@aau.edu.et/ twtigistw@gmail.com

2. Addis Ababa University, College of Natural and Computational Sciences, Department of Plant Biology and Biodiversity Management; P.O. Box 3434, National Herbarium of Ethiopia, Addis Ababa Ethiopia. Email address: sebsebe.demissew@aau.edu.et/sebseb.demissew@gmail.com

\begin{abstract}
Background: Pastoral communities of the Afar people in northeastern Ethiopia use medicinal plants for various health problems. However, very limited scientific documents are found addressing ethnomedicinal knowledge of the community. Objective: This study aimed at documenting herbal medicine and the associated knowledge from Koneba district of Afar Regional State, Ethiopia.

Methods: Purposive sampling method was used to select study sites and key informants. General informants were selected through simple random sampling methods. Semi-structured interviews and guided field walk were used to collect data while Informant Consensus Factor (ICF), Fidelity Level (FL) and Preference Ranking were used to analyze and verify data.

Results: A total of 67 medicinal plant species used to treat humans and livestock ailments were recorded and collected. Thirteen medicinal plant species were mentioned as effective medicine against snake bite (ICF; 0.68) while nine species used to treat malaria, common cold and fever (ICF: 0.67). Cyphostemma adenocaule (Steud. ex A.Rich.) Desc. ex Wild \& R.B.Drumm. was the most preferred species used to combat snakebite, which was prevalent in the area.

Conclusion: Snake bite, malaria, common cold and fever are common health problems in the study area. Efficient use of herbal medicine has minimized the impact of these diseases.
\end{abstract}

Keywords: Ethnomedicine; informant consensus; snakebite.

DOI: https://dx.doi.org/10.4314/ahs.v21i1.51

Cite as: Zeynu A, Wondimu T, Demissew S. Herbal medicine used by the community of Koneba district in Afar Regional State, Northeastern Ethiopia. Afri Health Sci. 2021;21(1):410-7. bttps:/ / dx.doi.org/10.4314/abs.v21i1.51

\section{Introduction}

The practice of herbal medicine has a long term history and culture among many African communities. This persistent interaction of people and herbal medicine is mainly due to recognition of healing effects of the system. ${ }^{1,2}$ Knowledge and use of medicinal plants in Ethiopia play important role in the primary health care needs for both human and livestock. A number of eth-

\section{Corresponding author: \\ Tigist Wondimu, \\ Addis Ababa University, \\ College of Natural and Computational \\ Sciences, Department of Plant Biology and \\ Biodiversity Management; \\ P.O. Box 30251, Addis Ababa, Ethiopia. \\ Email: tigist.wondimu@aau.edu.et/ \\ twtigistw@gmail.com}

nomedicinal studies documented this vital knowledge representing different communities from northern, southern and central parts of the country. For example: $3,4,5,6,7,8,9,10,11,12,13,14,15$. Relatively, few studies have been conducted in the northeastern ${ }^{16,17,18}$ and eastern ${ }^{19,20}$ parts of Ethiopia. These are areas where most of the pastoral community of Ethiopia reside.

The Afar Regional State lies in the arid and semiarid climatic zone of the northeastern Ethiopia within the Great Rift Valley. The topography varies from hilly escarpment in the western edge to lowland plain areas in the eastern part. According to ${ }^{21}$, the vegetation type is predominantly Acacia-Commiphora woodland and bushland in western part, small forest patches covered with Juniperous-Olea forest in northwestern part, and desert and semi-desert vegetation type in eastern plain land.

The Afar people are among the cultural and pastoral 
communities in Ethiopia who have developed knowledge on herbal medicine through long time interaction with nature. Their life style coupled with different life challenges, such as limited access to modern health care $^{22}$ has necessitated extensive use of plant resources as medicine. Despite this, very limited scientific studies have been conducted to retrieve the ethnomedicinal knowledge of the community. To-date, only ${ }^{16,17}$ and ${ }^{18}$ are the ethnomedicinal studies known from the Afar Region. Such scientific evidences help to enhance contribution of nature to development of herbal medicine. ${ }^{23}$ However, the current trend of biodiversity loss may affect availability of herbal species and the associated knowledge. This may also be accelerated by alteration of life style. ${ }^{24}$ Therefore, retrieval and documentation of such knowledge systems before they disappear is important.

The current study was conducted in Koneba district of the Afar Regional State with the aim of documenting medicinal plant species and the associated knowledge. The study also anticipated to see the role of protected areas and home gardens in the conservation of medicinal plants and securing the knowledge system.

\section{Methods}

\section{Study area}

The Afar Regional State is located in geographic location between $8^{\circ} 49^{\prime}$ and $14030^{\prime} \mathrm{N}$ latitude and $39^{\circ} 34^{\prime}$ to $42^{\circ} 28^{\prime}$ E longitude, northeastern Ethiopia. Koneba district is one of the 28 administrative districts, which is located in the northwestern part of the Regional State. It is about $624 \mathrm{~km}$ away from Addis Ababa, bordered by Tigray Regional State from the west, by Dallol district from north, and by Berhale district from east (Figure 1). The average elevation in this district is 1150 meters above sea level. ${ }^{25}$

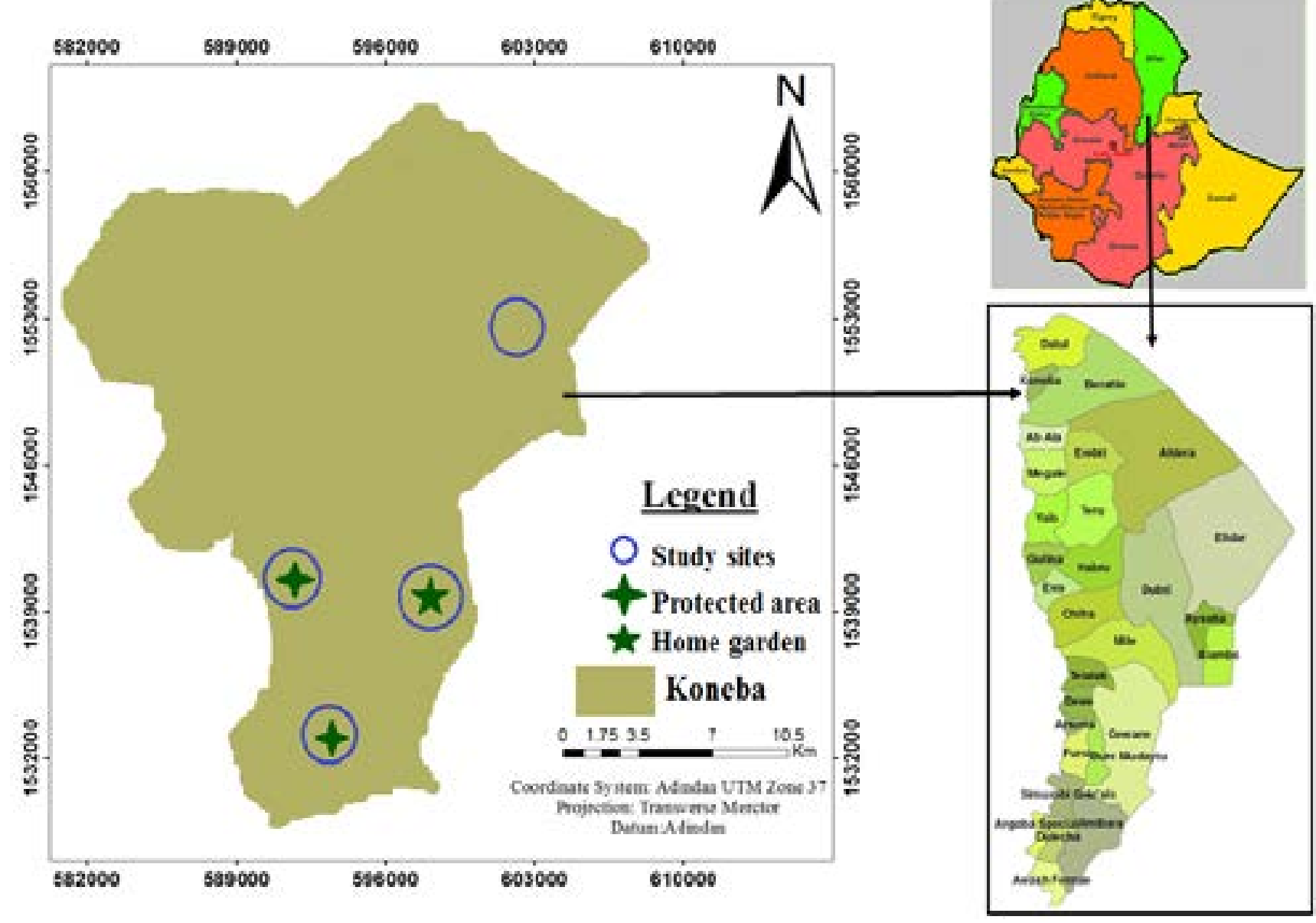

Figure 1: Study area and sampling sites

The population of Koneba is about 54,198 people who occupy, an area of $483.16 \mathrm{~km}^{2}{ }^{26}$ The majority of the local communities depend on livestock products and small-scale irrigation farming, which involves production of cereals, fruits and vegetables. A small proportion $(0.68 \%)$ engage in pastoral and urban $(5.59 \%)$ life styles. ${ }^{26}$

\section{Sampling, data collection and analyses}

Four kebeles (Smallest administrative unit in Ethiopia) were selected as study sites based on prior information from the administrative offices and based on site seen during the reconnaissance survey. Vegetation cover, proximity to plant resources and herbal medicine utilization were basis of site selection. A total of 60 inform- 
ants (50 males and 10 females) between the ages of 25 and 83 were selected to engage in this study. Eighteen traditional health practitioners were identified as key informants through purposive sampling technique following. ${ }^{27}$ General informant (42) were selected through simple random method following the method by ${ }^{28}$.

Ethnobotanical data were collected following techniques suggested in standard manuals, guidelines and protocols. ${ }^{29}, 30,31,32,33$ Formal and informal interviews were conducted individually and in groups. Active participant observation was employed in order to get firsthand information. ${ }^{34}$ Voucher specimens of the plants were collected and deposited at the National Herbarium of Ethiopia (ETH) as well as at the Herbarium of Traditional and Modern Medicine Directorate, Ethiopian Public Health Institute (EPHI).

Descriptive statistical tools were employed to analyze and summarize the data. Informant Consensus Factor (ICF) was calculated for each medicinal plant in order to validate responses of informants. 36 The difference between number of use citation (nur) and number of species used (nt) divided by the number of use citation minus one gives the value of ICF.

$$
\text { ICF }=\frac{n_{u r}-n_{t}}{n_{u r}-1}
$$

These values are presented between 0 and 1 , and validity of the information obtained from informants increase as the ICF value approaches to 1 . Fidelity level (FL) was calculated to verify the most important medicinal plant species in the district. The percentage of informants claiming a plant species for the same purpose provides the FL\% and was calculated using the following formula.

$\mathrm{FL} \%=\frac{\mathrm{Np}}{\mathrm{N}} X 100$

Where $\mathrm{Np}$ stands for the number of informants claiming a certain plant species to cure a particular disease while $\mathrm{N}$ is the number of informants that use the species as medicine to treat any given disease. ${ }^{30}$

Preference ranking was conducted following ${ }^{29}$, to identify the most preferred medicinal plant species used to treat the prevalent diseases in the area. Six medicinal plants mentioned by more than $50 \%$ of the total informants were used in this analysis. Each key informant was asked to assign the highest value (6) for the most preferred species and the lowest value (1) for the least preferred plant, and all the rest ranging between 6 and 1 . The value of each species was summed up and ranked based on the total score.

\section{Results}

\section{Medicinal plant diversity in Koneba district}

A total of 67 medicinal plant species belonging to 58 genera and 34 families were reported in this study. The families with largest number of species were Fabaceae (9 species), followed by Solanaceae $(7$ species) and Asclepidiaceae (5 species). Single species per single genus was recorded in the remaining 31 Families (Figure 2). Fifty three $(79.10 \%)$ species were used to combat human ailments while $10(15.15 \%)$ species used to treat both human and livestock ailments. Four (6.06 \%) species were reported as medicines of livestock.

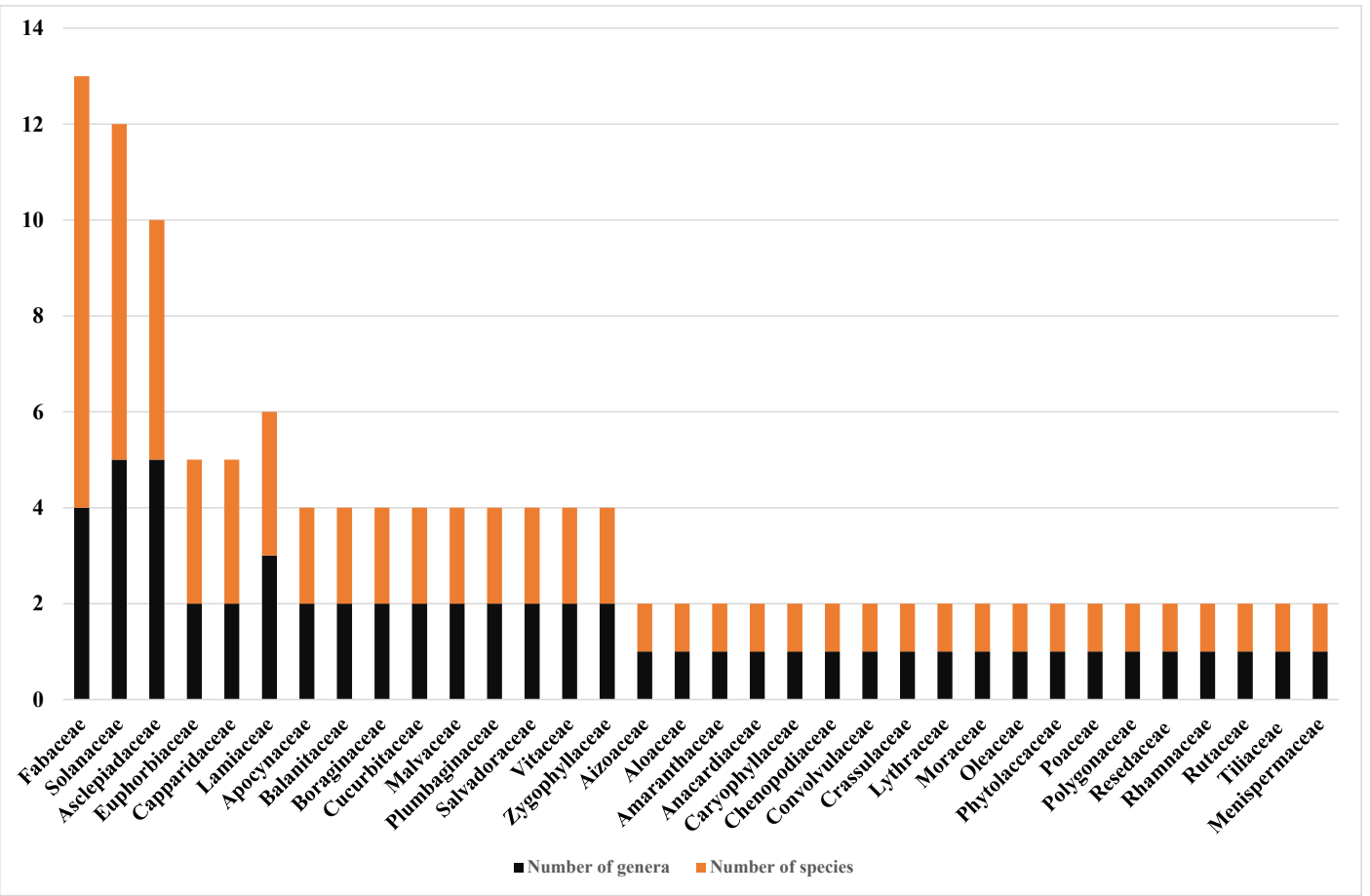

Figure 2: Taxonomic diversity and hierarchical composition of medicinal plants 


\section{Distribution, Habit and Parts used}

Thirty-three $(50 \%)$ of the species were collected from wild habitat while home gardens contributed 24 (36.36 $\%)$ species and $10(15.15 \%)$ species were obtained from protected areas. Analysis of diversity by habits showed $37.31 \%$ accounting for shrubs, $35.82 \%$ for herbs and $21 \%$ for trees. The remaining $5.97 \%$ of the species were Lianas.

Leaves and roots were the most commonly used parts accounting for $91(39.40 \%)$ and $63(27.28 \%)$ of the remedies mentioned by the informants, respectively. Most remedies were prepared from single plant part while fourteen remedies were prepared from combinations of either leaf and root (11), leaf and stem (two), or leaf and bark (one).
Mode of Preparation and ways of administration

Only nine percent of the mentioned mode of preparation employed dry materials. Pounding/crushing and mixing with either water or other additives were principal methods scoring 133 mentions; $57.08 \%$ (Table 1). Water is the popular solvent used to prepare the herbal remedies (109 mentions). Honey, milk, butter, oil, animal blood, or saliva were reported as important additives (47 mentions). Oral administration accounted for the highest proportion of remedy application $(114 ; 71.7$ $\%$ ) followed by topical administration (25; 15.72\%). Uses of fresh materials are the most frequently mentioned methods $(74.8 \%)$ while alternative use of fresh or dried materials were accounted for $17 \%$ of preparation modes.

Table 1 Mode of herbal medicine preparation

\begin{tabular}{|lcc|}
\hline Mode of Preparation & $\begin{array}{c}\text { Number } \\
\text { of } \\
\text { mentions }\end{array}$ & Percentage \\
Pounding/crushing \& mixing & 133 & 57.08 \\
Pounding/crushing & 63 & 27.04 \\
Boiling & 11 & 4.72 \\
Squeezing & 10 & 4.29 \\
Cooking & 8 & 3.44 \\
Burning & 2 & 0.86 \\
Others & 6 & 2.58 \\
\hline
\end{tabular}

Cultural importance of herbal medicine among Koneba communities in Afar

The highest ICF (0.68) was obtained for the use of herbal medicine (13 medicinal plant species) to handle health issues related with poison, mainly with snakebite
(Table 2). Nine species were mentioned to treat malaria, common cold, cough and fever scoring the second highest ICF value (0.67). The third highest ICF value (0.64) was recorded for problems related with reproductive health.

Table 2 Consensus factor support for disease categories reported by informants

\begin{tabular}{|lccc|}
\hline Category & Species & Use citation & ICF \\
Snake bite & 13 & 39 & 0.68 \\
Malaria, common cold, cough, fever & 9 & 25 & 0.67 \\
Impotency in men, sterility in women, abortion & 6 & 15 & 0.64 \\
Evil eye, devil spirit, mental disorder & 12 & 29 & 0.61 \\
Arthritis, acne-vulgaris, leprosy, cellulites & 15 & 36 & 0.60 \\
Dandruff, thorn removal, weapon removal & 6 & 13 & 0.58 \\
Gastritis and stomach upsets, typhoid & 15 & 29 & 0.55 \\
Kidney infection, urine retention, hepatitis & 10 & 20 & 0.53 \\
Wound, ulcers & 14 & 25 & 0.46 \\
Fire burn, skin cut, blood clotting & 5 & 9 & 0.44 \\
Ear and eye infection, animal eye infection & 9 & 14 & 0.38 \\
Tonsil, splenomegaly & 6 & 8 & 0.29 \\
Anthrax & 4 & 5 & 0.25 \\
Cancerous diseases & 5 & 6 & 0.20 \\
Tuberculosis (TB) and related diseases & 8 & 9 & 0.13 \\
\hline
\end{tabular}


Highest FL were obtained for Ziqiphus spina-christi (L.) percentages of FL were recorded for Balanites aegyotiaca Desf., Cocculus pendulus (J.R.Forst. \& G.Forst.) Diels, C. (L.) Delile, Chenopodium album L. and Acalypha fruticose adenocaule and Balanites rotundifolia (Tiegh.) Blatt. Good Forssk. (See Table 3).

Table 3 Application of the most commonly used medicinal plants and their fidelity level

\begin{tabular}{|llccc|}
\hline Plant name & Ailment category & Np & N & FL \\
Z. spina-christi & Dandruff & 3 & 3 & $100 \%$ \\
C. pendulus & Fire burn & 2 & 2 & $100 \%$ \\
C. adenocaule & Snake bite & 2 & 2 & $100 \%$ \\
B. rotundifolia & Malaria & 9 & 9 & $100 \%$ \\
Balanites aegyptiaca (L.) Delile & Wounds & 7 & 10 & $70 \%$ \\
Chenopodium album L. & Urine retention & 2 & 3 & $67 \%$ \\
Acalypha fruticosa Forssk. & Stomach swelling & 2 & 3 & $67 \%$ \\
Acacia oerfota (Forssk.) Schweinf. & Common cold & 3 & 6 & $50 \%$ \\
Ehretia obtusifolia Hochst. ex A.DC. & Liver diseases & 2 & 4 & $50 \%$ \\
Cucumis dipsaceus Ehrenb. ex Spach & Arthritis & 2 & 4 & $50 \%$ \\
Acacia mellifera (M.Vahl) Benth. & Eye infection & 2 & 4 & $50 \%$ \\
Achyranthes aspera L. & Arthritis & 2 & 6 & $33 \%$ \\
\hline
\end{tabular}

Among the six most cited medicinal plant species that preferred most while Zaleya pentandra (L.) C.Jeffrey were used against snakebite, Cyphostemma adenocaule was ranked last (Table 4).

Table 4 Preference ranking of medicinal plants used against snakebite

\begin{tabular}{|c|c|c|c|c|c|c|c|c|c|}
\hline \multirow[t]{2}{*}{ Medicinal Plants } & \multicolumn{7}{|c|}{ Informants } & \multirow[t]{2}{*}{ Average score } & \multirow[t]{2}{*}{ Rank } \\
\hline & I1 & $\mathbf{I} 2$ & I3 & I4 & $\mathbf{I 5}$ & I6 & I7 & & \\
\hline C. adenocaule & 6 & 3 & 6 & 5 & 4 & 6 & 6 & 36 & $1^{\mathrm{st}}$ \\
\hline C. quadrangularis & 5 & 5 & 1 & 6 & 6 & 4 & 4 & 31 & $2^{\text {nd }}$ \\
\hline Citrus aurantifolia (Christm.) & 4 & 6 & 4 & 3 & 3 & 5 & 3 & 28 & $3^{\text {rd }}$ \\
\hline \multicolumn{10}{|l|}{ Swingle } \\
\hline Nicotiana glauca Graham & 2 & 1 & 3 & 4 & 5 & 3 & 5 & 23 & $4^{\text {th }}$ \\
\hline Commicarpus & 3 & 4 & 2 & 2 & 1 & 2 & 2 & 16 & $5^{\text {th }}$ \\
\hline \multicolumn{10}{|l|}{ plumbagineus A.Rich. } \\
\hline Z. pentandra & 1 & 2 & 5 & 1 & 2 & 1 & 1 & 13 & $6^{\text {th }}$ \\
\hline
\end{tabular}

\section{Discussion}

In this study, a substantial number of medicinal plant species were recorded and collected that justified the use of medicinal plants by the Afar pastoral community. The largest number of medicinal plant species collected in this study belong to the family Fabaceae. This family is the third largest angiosperm family and widely distributed globally (Encyclopedia Britannica) while it is the second largest in the Flora region. ${ }^{36}$ It includes many species that are economically important. ${ }^{37}$ The families Solanaceae and Asclepidiaceae also include several species that are typical of arid environments such that of the Afar region.

The proportion of shrubs was high in the current study, 
which is in agreement with preveious studies. ${ }^{1,16,4,17,18}$ This is because of the influence from the dominant vegetation type, which is mainly Acacia-Commiphora woodland and bushland. ${ }^{21}$ Composition of herbs was also comparable to that of shrubs, which could be the contribution of the home garden. Trees also contributed a good number of medicinal plant species, which could be the effect of protection.

The highest proportions of herbal medicines are prepared from fresh leaves and roots. This is consistent with findings of other studies. ${ }^{3,1,7,18}$ Preparing herbal medicines from fresh materials reduces the risk of losing active bioactive ingredients due to drying and poor storage. Leaves are the most usable parts in many cases of herbal medicine. This is attributed to higher concentration of bioactive ingredients produced and stored in leaves than other parts. ${ }^{38,39}$ Roots accounted for eleven kinds of remedies, which demonstrates the existence of bioactive ingredients in roots. ${ }^{40}$

Honey, sugar and salt were used to provide the prepared herbal medicines taste as reported in similar studies. ${ }^{16,17}$ Use of milk and animal blood were believed to increase the potency of medicinal plants ${ }^{16}$ while milk is reported as antidote in case of toxicity and stomach upset. ${ }^{18}$

The result of ICF analyses indicated highest value to the disease category that included snakebite, malaria, common cold and related diseases. The use of a number of plants to handle a certain disease and the high agreement among several respondents implies high prevalence of the disease. Largest number of medicinal plant species (13 species) were cited to treat single type of disease (snakebite) while nine species were mentioned to treat more than one disease (malaria, common cold, cough and fever). Hence, snakebite is the prevalent disease identified in the study area, which is similar to findings of studies conducted elsewhere in the region. ${ }^{16}$ Cyphostemma adenocaule is identified as the most preferred species used to treat snakebite. This result is supported by the FL analysis. A review report by ${ }^{41}$ included the species as one of the medicinal plant species used by local communities of Afar as well as the neighboring Tigray and Oromiya regions. Another species belonging to the same genus was reported as useful herb against snakebite Yalo district of Afar region. ${ }^{18}$ The bioactive constituents having detoxifying effect might have been confined at genus level. Zaleya pentandra was also reported as useful plant against snakebite, which agree with the report by ${ }^{16}$. These findings suggest that such shared knowledge might be the reflection of interaction with the actual biodiversity in the area.
Despite these findings, snakebite has not been reported among the list of health problems by the modern health care system. This evidenced that the problem is controlled by herbal medication system. The contribution of these species could have been extended to tackle other related health problems. Evaluating and validating the efficacy can promote the benefit of the species.

\section{Acknowledgements}

All informants are given the highest respect and recognition for their unreserved information on herbal medicine used in the study district. This work was supported by the Office of Graduate Studies, Addis Ababa University, Addis Ababa, Ethiopia and the Traditional and Modern Medicine Directorate at Ethiopian Public Health institute (EPHI), Ethiopia. Alexanader von Humboldt Foundation Alumni project and SEWiST (Society of Ethiopian Women in Science and Technology) are acknowledged for the provision of writing skill during which this paper was drafted.

\section{Conflict of interest}

None declared.

\section{References}

1. Balemie K. Kelbessa E., Asfaw Z. Indigenous medicinal plant utilization and management threats in Fentalle area, Eastern Shewa, Ethiopia. Ethiopian Journal of Biological Society, 2004; 3:1-58.

2. Kebede D, Amberbir A. Getachew B., Mussema Y. A historical overview of traditional medicine practices and policy in Ethiopia. Ethiopian Journal of Health Science, 2006; 20:127-134.

3. Giday M., Asfaw Z. Equist T., Woldu Z. An Ethnobotanical Study of Medicinal plants used by the Zay people in Ethiopia. Journal of Ethnopharmacology, 2003; 85: 43-52.

4. Hundie D., Asfaw Z., Kelbessa E. Use of traditional medicinal plants by the people of 'Boosat' sub-district, Central-eastern Ethiopia. Ethiopian Journal of Health Sciences, 2006; 16: 141- 155.

5. Giday M, Teklehaymanot T, Animut A, Mekonnen Y. Medicinal plants of the Shinasha, Agew-Awi and Amhara peoples in northwest Ethiopia. Journal of Ethnopbarmacology, 2007; 110:516-525.

6. Teklehymanot T., Giday M. Ethnobotanical study of medicinal plants used by people in Zegie peninsula, northwestern Ethiopia. Journal of Ethnobiology and Ethnomedicine, 2007; 3:12.

7. Wondimu T., Ensermu K., Asfaw Z. Ethnobotanical 
Study of Medicinal Plants Around 'Dheera' town, Arsi, Ethiopia. Journal of Ethnopharmacology, 2007; 112: 15216.

8. Lulekal E., Kelbessa E., Bekele T., Yineger H. An ethnobotanical study of medicinal plants in Mana Angetu district, south-eastern Ethiopia. Journal of Ethnobiology and Ethnomedicine, 2008; 4:10.

9. Yineger H., Yewhalaw D., Teketay D. Ethnomedicinal plant knowledge and practice of the Oromo ethnic group in southwestern Ethiopia. Journal of Ethnobiology and Ethnomedcine, 2008; 4:11.

10. Giday M, Asfaw Z, Woldu Z., Teklehymanot T. Medicinal plant knowledge of the Bench ethnic group of Ethiopia: an ethnobotanical investigation. Journal of Ethnobiology and Ethnomedicine, 2009; 5: 34.

11. Giday M, Asfaw Z, Woldu Z. Ethnomedicinal study of plants used by Sheko ethnic group of Ethiopia. Journal of Ethnopharmacology, 2010; 132:75-85.

12. Lulekal E., Asfaw Z., Kelbessa E., Van Damme P. Ethnomedicinal study of plants used for human ailments in Ankober district, North Showa zone, Amhara region, Ethiopia. Journal of Ethnobiology and Ethnomedicine, 2013; 9:63.

13. Tolossa K., Debela E., Athanasiadou S., Tolera A., Ganga G., Houdijk JGM. Ethnomedicinal study of plants used for treatment of human and livestock ailments by traditional healers in South Omo, southern Ethiopia. Journal of Ethnobiology and Ethnomedicine, 2013; 9: 32.

14. Biya A., Raga D., Denu D. Ethnobotanical study of medicinal plants in Dedo district, Jimma zone, Southwest Ethiopia. Journal of Medicinal Plants Studies, 2017; 5: 90-95.

15. Tefera BN., Kim Y-D. Ethnobotanical study of medicinal plants used as antimalarial and repellent by Sidama people of Hawassa Zuria district, Southern Ethiopia. Journal of Complementary Medicine Research, 2019; 10: 13-26.

16. Seifu T. Asres K., Gebre-Mariam T. Ethnobotanical and Ethnopharmaceutical Studies on Medicinal Plants of Chifra District, Afar Region, North Eastern Ethiopia. Journal of Ethiopian Pharmacology, 2006; 24, 41-58.

17. Giday M., Teklehaimanot T. Ethnobotanical study of plants used in management of livestock health problems by Afar people of Ada'ar District, Afar Regional State, Ethiopia. Journal of Ethnobiology and Ethnomedicine, 2013; 9:8.

18. Teklehaymanot T. An ethnobotanical survey of medicinal and edible plants of Yalo Woreda in Afar regional state, Ethiopia. Journal of Ethnobiology and Ethnomedicine, 2017; 13: 1-25.
19. Belayneh A., Asfaw Z., Demissew S., Bussa N. Medicinal plants potential and use by pastoral and agro-pastoral communities in Erer Valley of Babile Wereda, Eastern Ethiopia. Journal of Ethnobiology and Ethnomedicine, 2012; 8: 42.

20. Belayneh A., Bussa N. Ethnomedicinal plants used to treat human ailments in the prehistoric place of Harla and Dengego valleys, eastern Ethiopia. Journal of Ethnobiology and Ethnomedicine, 2014; 10:18.

21. Friis I., Demissew S., Paulo B. Atlas of the potential vegetation of Ethiopia. The Royal Danish Academy of Sciences and Letters, Denmark, 2010.

22. Philpott J., Abera A., Hadgu K. Livelihood/Emergency Assessment in Afar Region. Oxfam International 2005; Pp: 1-50.

23. Gemeda N., Tadele A., Girma B., Teka F. Ethiopian Traditional Medicine: Past, Current and Future. In: Proceedings of the Workshop on "Ethiopian Traditional Medicine: Past, Current and Future. Gemeda N., Tadele A., Girma B., Teka F. (eds.). Ethiopian Public Health Institute Addis Ababa, Ethiopia, 2015.

24. Reda KT. Social organization and cultural institutions of the Afar of Northern Ethiopia. International Journal of Sociology and Anthropology, 2011; 3: 423-429.

25. Ejara H. Baseline Survey of 55 Districts of PCDP Phase II, Part I, Annex 1, 2008.

26. CSA (Central Statistical Authority Census). Afar region: Central Statistical Authority, Addis Ababa, 2007.

27. Plays T. Purposive sampling. In: the Sage Encyclopedia of qualitative research methods, Given LM. (ed.). Sage 2; pp: 697-698. Los Angeles, 2008.

28. Moore DS. The Basic Practice of Statistics, fourth edition, Freeman, 2007.

29. Martin, G.J., Ethnobotany: a 'People and Plants' Conservation Manual. Chapman and Hall, London, $1995.268 \mathrm{pp}$.

30. Alexiades M. Collecting ethnobotanical data, an introduction to basic concepts and techniques. In: Selected Guideline for Ethnobotanical Research: A Field Manual, Alexiades M. and Sheldon J. W. (eds.). New York, U.S.A., 1996.

31. Höft M., Barik SK., Lykke AM. Quantitative ethnobotany. Applications of multivariate and statistical analyses in ethnobotany. People and Plants Working Paper 6. United Nations Educational, Scientific and Cultural Organization (UNESCO), Paris, 1999.

32. Vogl C.R., Vogl-Lukasser B. Tools and Methods for Data Collection in Ethnobotanical Studies of Homegardens. Field Methods, 2004; 16: 285-306.

33. Cámara-Leret R., Paniagua-Zambrana N., Macía MJ. A Standard Protocol for Gathering Palm Ethnobotani- 
cal Data and Socioeconomic Variables across the Tropics 2012; (http://www.fp7-palms.org).

34. Kawulich BB. Participant observation as a data collection method. Forum Qualitative Social Research, 2005; 6. 35. Andrade-Cetto A., Heinerich M. From the field into the lab: useful approaches to selecting species based on local knowledge. Frontier in Pharmacology, 2011.

36. Hedberg O., Edward S. Forward message. In: Flora of Ethiopia, volume III. Hedberg O. and Edward S. (eds.), pp: xiii, Uppsala, 1989.

37. Thulin M. Leguminosae of Ethiopia. Opera Botnicie, 1983; 68, 14-223.

38. Agbafor KN. Engwa AG., Obiudu IK. Analysis of Chemical Composition of Leaves and Roots of Ager- atum conyzoides. International Journal of Current research and Academic Review, 2015; 3: 60-65.

39. Monsurat WO., Chatherine EQ. Variation in the Phytochemical Constituents of Seeds, Mature and Immature Leaves of Moringa oleifera Lam. Growing in Five Local Government Areas of Oyo State, Nigeria. Journal of Natural Sciences Research, 2016; 6:54-60.

40. Sai Prasana CG., Poongani M., Karpagama S. Phytochemical content of the leaf, stem and root of Micrococca mercurialis (L.)Benth. A promising herb. Journal of Pharmacy and Biological Sciences, 2015; 10: 24-27.

41. Yirgu A., Chippaux J-P., Ethnomedicinal plants used for snakebite treatments in Ethiopia: a comprehensive overview. Journal of Venomous animals and Toxins Including Tropical Diseases, 2019; 25: e20190017. 